\title{
Current Challenges of Liver Transplantation in Iran
}

\author{
Reza F. Saidi ${ }^{1,3,}$, Seyed Mohammad Kazemaini², Reza Malekzadeh ${ }^{3}$
}

1. Department of Surgery, Shariati Hospital, Tehran University of Medical Sciences, Tehran, Iran

2. Management Center for Transplantation, Ministry of Health and Medical Education, Tehran, Iran

3. Liver and Pancreaticobilliary Research Center, Digestive Disease Research Institute, Shariati Hospital, Tehran University of Medical Sciences, Tehran, Iran

\footnotetext{
* Corresponding Author:

Reza F. Saidi, MD, FICS, FACS

Department of Surgery,

Shariati Hospital, Digestive Disease

Research Institute, Tehran University of

Medical Sciences, Tehran, Iran

Tel: + 982182415104

Fax: + 982188633039

Email: rfsaidi@hotmail.com
}

Received: 10 Sep. 2017

Accepted: 11 Dec. 2017

\section{ABSTRACT}

Liver transplantation (LT) is a lifesaving procedure and the treatment of choice for patients suffering from end-stage liver disease (ESLD). There is increasing number of patients with ESLD in Iran. There is a need to expand and develop new centers to provide better access to LT for patients with ESLD in Iran. This review will address current and future challenges for LT in Iran.

\section{KEYWORDS:}

Liver transplantation, Cirrhosis, Viral infections

Please cite this paper as:

F. Saidi R, Kazemaini SM, Malekzadeh R. Current Challenges of Liver Transplantation in Iran. Middle East J Dig Dis 2018;10:45-49. doi: 10.15171/mejdd.2017.90.

INTRODUCTION

Liver transplantation (LT) is a lifesaving procedure and the treatment of choice for patients suffering from end-stage liver disease (ESLD). The first successful LT in Iran was performed at Shiraz University of Medical Sciences in 1992. ${ }^{1}$ Since then, several LT programs were developed throughout the country. ${ }^{2,3}$ However due to increasing number of patients with ESLD, there is a need to expand and develop new centers to provide better access to LT for patients with ESLD in Iran. This review will address current and future challenges for LT in Iran.

\section{Chronic Liver Disease and Current Status of LT in Iran}

Chronic liver diseases including liver cancer are presently the $5^{\text {th }}$ common etiology of mortality in Iran with more than 8000 deaths per year. ${ }^{4,5}$ The most common cause of ESLD was HBV-related cirrhosis until 2005. ${ }^{4}$ Following the universal neonatal HBV vaccination in 1992 and adulthood vaccination in 2005, the incidence of new HBV infection in Iran declined dramatically. Presently the most common cause of ESLD is cryptogenic cirrhosis, which include mainly steatohepatitis in men and autoimmune hepatitis in women. ${ }^{5,6}$ Cholestatic liver disease especially primary sclerosing cholangitis is also increasing due to the emergence of inflammatory bowel disease (IBD) epidemic in Iran. ${ }^{7,8}$ Hepatitis $\mathrm{C}$ and alcoholic cirrhosis are not common and the plan for $\mathrm{HCV}$ eradication with very effective new generation of anti-HCV medication would make LT much less common in near future. ${ }^{9}$ Non-alcoholic fatty 

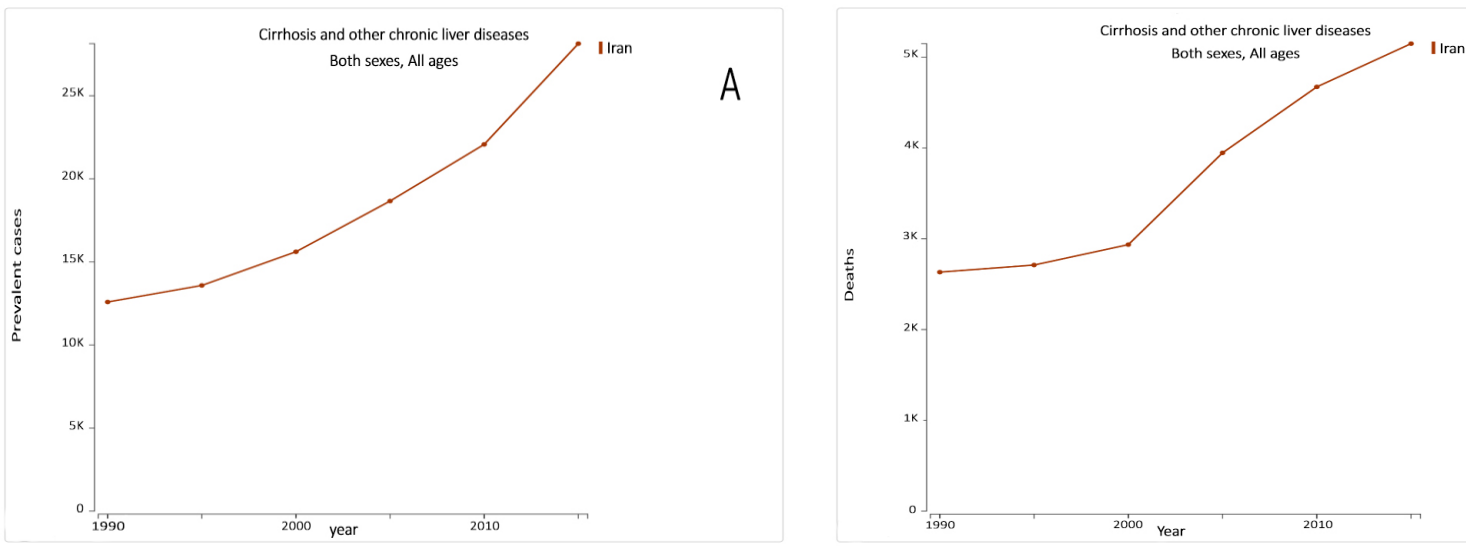

Fig.1: The prevalence (A.) and mortality (B.) of cirrhosis and chronic liver diseases in Iran (1990-2015)

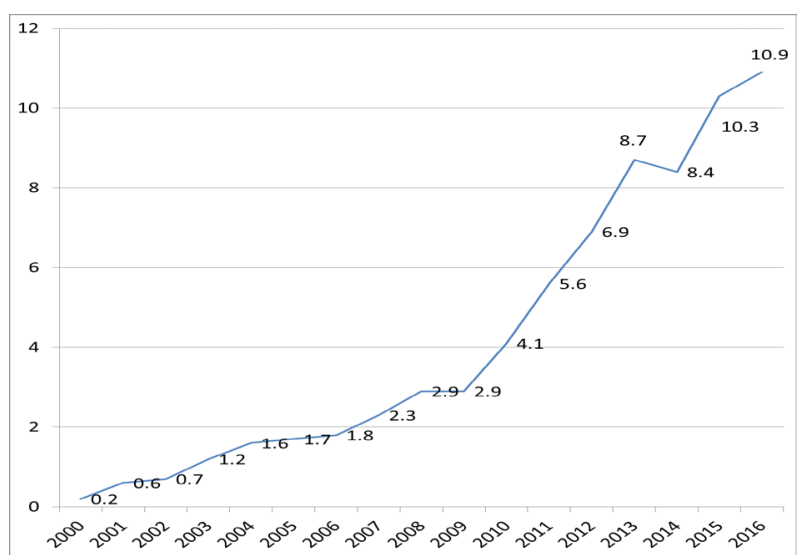

Fig.2: Brian death donation per million in Iran

liver disease (NAFLD) is presently the most common type of liver disease in Iran and its incidence is on the rise. ${ }^{9}$ ESLD secondary to viral infections, autoimmunity, and NAFLD constitute the etiology of up to $70 \%$ of admissions and mortalities at a major academic center in Iran for both sexes. ${ }^{10}$

Malekzadeh $^{6}$ and her colleagues studied more than 120,000 deaths in Iran in 2010. Among adults aged between 15 to 49 years, the main causes of death were gastrointestinal (GI) and liver cancers, and cirrhosis. Their findings showed similar results even among adults older the 50 years. Sepanlou and her colleagues also showed that from 1990 to 2010, there were approximately 8000 deaths annually due to cirrhosis and its complications in Iran. ${ }^{7}$ The authors estimated that there were annually 2500 deaths because of HBV cirrhosis, 3400 deaths caused by

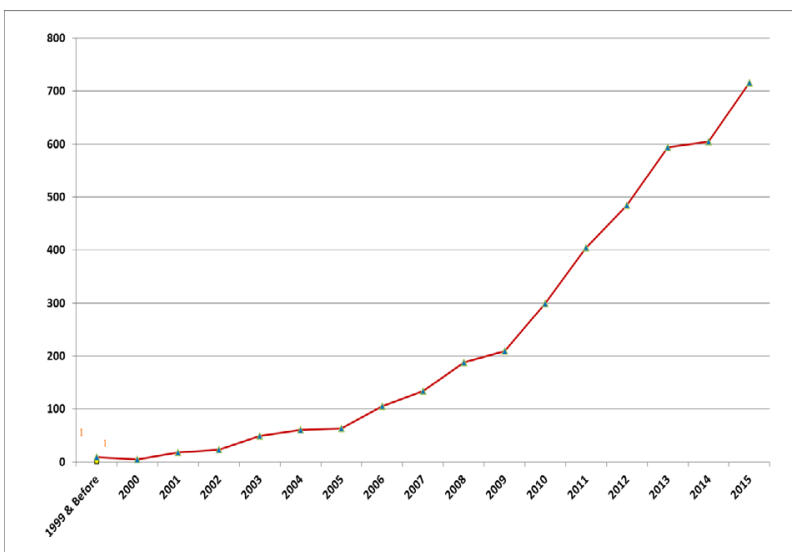

Fig.3: Number of liver transplantations performed on a yearly basis

NAFLD, 1600 deaths caused by HCV cirrhosis, and 500 deaths due to cholestatic liver disease in Iran. ${ }^{7}$ Current data (figure 1) showed that during 1990-2015 the prevalence and mortality of liver diseases in Iran is on the rise. ${ }^{11}$

A recent study at Shiraz University of Medical Sciences in Iran showed a similar trend (table 1). HBV and cryptogenic cirrhosis (most likely due to NAFLD) were the most common indications for LT at this center. ${ }^{1}$

Since the Iranian Parliament passed Donation after Brain Death Act in 2000, there has been expansion of deceased donations in Iran. Currently, per million donations is $10 .{ }^{9}$ which ranked Iran $26^{\text {th }}$ in the world (figure 2).

The first LT program in Iran was established at Nemazee Hospital in Shiraz. Currently, there are 
Table 1: Liver transplantation activities at different programs in Iran (1990-2016)

\begin{tabular}{lccc}
\hline \multicolumn{1}{c}{ Hospital } & Living Donors & Deceased donors & Total \\
\hline Nemazee Hospital, Shiraz & 397 & 3450 & 3847 \\
\hline Imam Khomeini Hospital, Tehran & 1 & 579 & 580 \\
\hline Montaseiah Hospital, Mashhad & & 137 & 137 \\
\hline Taleghani Hospital, Tehran & & 113 & 113 \\
\hline Afzalipoor Hospital, Kerman & 398 & 50 & 50 \\
\hline Alzahra Hospital, Isfahan & & 29 & 29 \\
\hline Golestan Hospital, Ahvaz & 7365 & 7743 \\
\hline Total & & 7 & \\
\hline
\end{tabular}

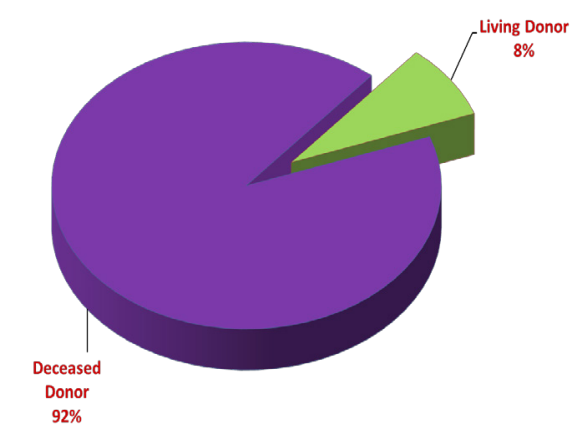

Fig.4: Source of liver allografts in Iran

seven programs in the country. There have been more than 4500 cases of LT performed in Iran. The number of LT performed in the country is currently around 800 cases annually (figure 3 ).

Most LTs are from deceased donors, although some cases of live donor liver transplantation have been performed too (figure 4). The rate of deceased donation especially liver allograft donation per million is on the rise in Iran (figure 5). Table 1 shows overall LT activities in different programs in Iran.

\section{LT in Iran: Challenges and Opportunities}

There are several LT programs in Shiraz, Tehran, Mashhad, Kerman, and Isfahan..$^{1-3}$ However, most of the provinces do not have a program. Approximately 800 LTs are annually performed, which is well below current need. ${ }^{1-3}$ To guarantee access to LT for all Iranian patients with ESLD in need of this life-saving service, there is

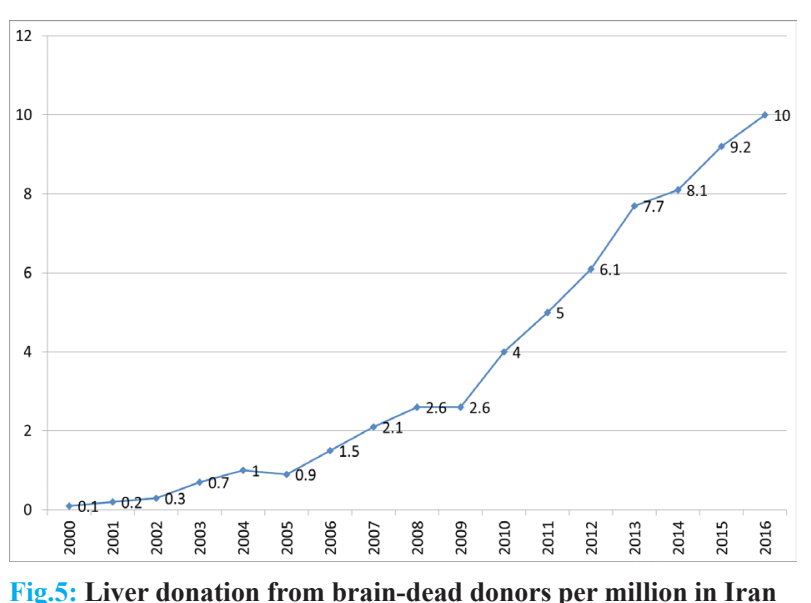

a need to have more centers throughout the country. There has been a good progress in the past two decades to expand access to transplantation in Iran such as development of deceased donor program in addition to live donation. However, there are several challenges to expand the access to LT in Iran as follows:

\section{1- Lack of a national transplantation system}

Although there are several LT programs in Iran, there is no national transplantation system to coordinate the transplantation activities. Each program is currently functioning independently and there is limited cooperation and collaboration among the centers. There is no registry system and database for LT in Iran. This issue makes quantitative and qualitative assessment more difficult. There is a need to develop a stronger national transplantation system to coordinate the care, improve the quality, and provide national organ sharing. 


\section{2- Lack of legal platform}

The only national law regarding organ donation and transplantation was passed by the Parliament 17 years ago, which authorized the utilization of organs from brain-dead donors for transplantation. ${ }^{3}$ There is a need to have a legal platform to develop a national transplantation system. Historically, 1984 National Transplant Act in the US led to creation of the United Network for Organ Sharing (UNOS) and expansion of transplantation. ${ }^{12}$ European countries also followed the same path, which led to formation of Eurotransplant network. ${ }^{13}$ There is also such a need in Iran. We hope that with cooperation between executive and legislative branches such a legal platform would be established. This would lead to establishment of an organized national organ procurement and transplantation network in Iran. Such a network will also help to improve the quality and access of the patients to transplantation care especially LT.

\section{3- Lack of national organ procurement and trans- plantation registry}

Quality data are essential for future planning. Each individual program in Iran has its own database. However there is a need to a national database. All the LT programs should be required by law to provide their data. This database can be used to improve the quality, identify the problems, and plan for possible solution to improve patients' care.

\section{4- Need to increase public awareness regarding organ donation}

There has been a significant progress regarding organ donation in Iran. Donors per million population (PMP) has increased to 25 in recent years. ${ }^{14}$ There have been 5000 brain-dead donors in Iran last year. However only 1500 proceeded to organ donation due to low conversion rate. ${ }^{15}$ There is a need to increase public awareness regarding organ donation. There is still no deceased donor program in several provinces in Iran. ${ }^{3}$ Increase in public awareness and development of more deceased donation networks throughout the country would lead to improve public access to transplantation in Iran.

\section{5- Lack of adequate liver transplantation centers}

Iran has several LT programs in Shiraz, Tehran,
Mashhad, Kerman, and Isfahan. ${ }^{1-3}$ Excluding the centers at Shiraz University of Medical Sciences and Tehran University of Medical Sciences, ${ }^{1,2}$ the remaining centers are low volume. ${ }^{3}$ These centers cannot provide adequate care to all patients with ESLD. There is a need to develop several other centers in different geographic locations to ensure access of all patients with ESLD to LT. This will require financial support and adequate professional personnel.

\section{6- Lack of adequate training programs}

There is a need to ensure training of enough experienced and professional personnel to expand access to LT in Iran. There are very few such training programs. ${ }^{1,2}$ There are only two approved surgical transplantation fellowships in the country. There should be enough programs to train nurses, physicians, and allied health professionals regarding the transplantation in general and especially for LT.

\section{7- Financial and insurance issues}

LT is a lifesaving and expensive procedure. Almost $85 \%$ of the costs of liver transplantations are covered by the government's insurance. The post-transplantation care is also expensive especially the cost of life-long immunosuppression, which is also partially covered by the insurance. There should be a national effort to support patients in need of LT financially with adequate insurance coverage.

In summary, there is an increased need for LT in Iran. A national organ procurement and transplantation network is required to meet this need, improve the quality of care and access to LT for all patients with ESLD in Iran.

\section{ETHICAL APPROVAL}

There is nothing to be declared.

\section{CONFLICT OF INTEREST}

The authors declare no conflict of interest related to this work.

\section{REFERENCES}

1. Malek-hosseini SA, Salahi H, Lahsaee M, Bahador A, Lankarani MB, Imanieh MH, et al. Initial experience with liver transplantation in Iran. Transplant Proc 2003;35:375-6. doi: 10.1016/S0041-1345(02)03844-7. 
2. Jafarian A, Nassiri-Toosi M, Najafi A, Salimi J, Moini M, Azmoudeh-Ardalan F,et al. Establishing a liver transplantation program at Tehran University of Medical Sciences, Iran: a report of ten years of experience. Arch Iran Med 2014;17:81-3.

3. Broumand B. Transplantation activities in Iran. Exp Clin Transplant 2005;3:333-7.

4. Ganji A, Malekzadeh F, Safavi M, Nasseri Moghaddam S, Nouraie M, Merat S, et.al. Digestive and Liver Disease Statistics in Iran. Middle East J Dig Dis 2009;1:56-62.

5. Stanaway JD, Flaxman AD, Naghavi M, Fitzmaurice C, Vos T, Abubakar I, et al. The global burden of viral hepatitis from 1990 to 2013: findings from the Global Burden of Disease Study 2013.Lancet 2016;388:108188. doi: 10.1016/S0140-6736(16)30579-7.

6. Malekzadeh F, Sepanlou SG, Poustchi H, Naghavi M, Forouzanfar MH, Shahraz S, et al. Burden of Gastrointestinal and Liver Diseases in Iran: Estimates Based on the Global Burden of Disease, Injuries, and Risk Factors Study, 2010. Middle East J Dig Dis 2015;7:138-54.

7. Sepanlou SG, Malekzadeh F, Naghavi M, Forouzanfar MH, Shahraz S, Moradi-Lakeh M, et al. Trend of Gastrointestinal and Liver Diseases in Iran: Results of the Global Burden of Disease Study, 2010. Middle East J Dig Dis 2015;7:121-37.

8. Malekzadeh MM, Vahedi H, Gohari K, Mehdipour P, Sepanlou SG, Ebrahimi Daryani N et al. Emerging Epidemic of Inflammatory Bowel Disease in a Middle Income Country: A Nation-wide Study from Iran. Arch Iran Med 2016;19:2-15.

9. Hajarizadeh B, Razavi-Shearer D, Merat S, Alavian SM, Malekzadeh R, Razavi H. Liver Disease Burden of Hepatitis C Virus Infection in Iran and the Potential Impact of Various Treatment Strategies on the Disease Burden. Hepat Mon 2016;16:e37234. doi:10.5812/hepatmon.37234

10. Shiefteh Abedian, Hossein Asl Soleimani, Mehdi Saberifiroozi, Reza Malekzadeh. Common Digestive and Liver Diseases among 5880 Patients Admitted to Shariati Hospital,Tehran,Iran during 20002009. Middle East J Dig Dis 2012;4:28-33.

11. https://vizhub.healthdata.org/gbd-compare/ (accessed July 26th 2017)

12. Schaeffer MJ, Alexander DC. U.S. system for organ procurement and transplantation. Am J Hosp Pharm 1992;49:1733-40.

13. https://eurotransplant.org/cms/index.php?page=about brief.

14. Najafizadeh K, Abbasi A, Ghorbani F, Radpei B, Kashani BS, Ahmadi ZH, et al.Organ retrieval from brain-dead patients by a single organ procurement center in Iran. Transplant Proc 2009;41:2723-5. doi: 10.1016/j.transproceed.2009.06.145.
15. Ghorbani F, Khoddami-Vishteh HR, Ghobadi O, Shafaghi S, Louyeh AR, Najafizadeh K. Causes of family refusal for organ donation. Transplant Proc 2011;43:4056. doi: 10.1016/j.transproceed.2011.01.031. 